\title{
AVALIAÇÃO DA ROCHA FONOLITO COMO FERTILIZANTE ALTERNATIVO DE POTÁSSIO
}

\author{
A. M. S. Teixeira', J. A. Sampaio', F. M. S. Garrido ${ }^{2}$ e M. E. Medeiros ${ }^{2}$ \\ ${ }^{1}$ Centro de Tecnologia Mineral - Ministério da Ciência, Tecnologia e Inovação \\ ${ }^{2}$ Instituto de Química - Universidade Federal do Rio de Janeiro \\ Haline_santos@ufrj.br
}

Artigo submetido em setembro/2012 e aceito em novembro/2012

\section{RESUMO}

Nos últimos anos, vêm sendo realizadas pesquisas sobre o possível aproveitamento de silicatos de potássio para produção e/ou aplicação como fertilizantes potássicos, devido a crescente dependência externa do Brasil. A rochagem é uma prática de agricultura alternativa que ajuda a recuperar solos pobres e a renovar a fertilização de áreas de exploração agrícola por meio da incorporação de rochas moídas ao solo. Neste contexto, o objetivo deste trabalho é avaliar as características físicas e químicas da rocha fonolito, proveniente do Planalto de Poços de Caldas, MG, conforme os parâmetros para avaliação de fertilizantes potássicos, estabelecidos pelo Ministério da Agricultura, Pecuária e Abastecimento. O fonolito em estudo possui cerca de $9 \%$ de $\mathrm{K}_{2} \mathrm{O}$, além de outros nutrientes que também são requeridos pelas plantas, como $\mathrm{Mn}, \mathrm{Ca}$ e Fe. Os principais minerais que constituem a rocha, identificados por DRX, são: microclínio e ortoclásio, confirmando que a sua mineralogia principal é formada por minerais de feldspato potássico. A análise dos resultados de IV e FRX corroboram com as fases observadas por DRX. A análise destes resultados indica que a rocha fonolito possui potencial para aplicação na agricultura como insumo alternativo de potássio.

PALAVRAS-CHAVE: Fonolito, fertilizante potássico, rochagem.

\section{EVALUATION OF PHONOLITE ROCK AS A POTASSIUM FERTILIZER ALTERNATIVE}

\section{ABSTRACT}

In recent years, research has been conducted on the possible use of potassium silicates for the production and/or application as potash fertilizers, due to the increased Brazilian external dependence. The stonemeal is an alternative agriculture method that helps to restore and renew the soils poor fertilization of degraded areas through the incorporation of ground rock to the soil. In this context, the objective of this work is to evaluate the physical and chemical characteristics of the phonolite rock, from Poços de Caldas plateau, MG, southern Minas Gerais, in Brazil, according to parameters for potash fertilizer, established by Ministry of Agriculture, Livestock and Supply. The phonolite in study has about $9 \% \mathrm{~K}_{2} \mathrm{O}$ and others nutrients which are also required by plants, such as $\mathrm{Mn}, \mathrm{Ca}$ and Fe. The main mineral rock components were identified as: microcline and orthoclase, which confirm the primary mineralogy of the phonolite studied is feldspar minerals. Furthermore, IR and FRX analysis results corroborate the phases observed by XRD. Analysis of these results indicates that the phonolite rock has potential for application in agriculture as potassium alternative feedstock.

KEY-WORDS: Phonolite, potash fertilizer, stonemeal. 


\section{AVALIAÇÃO DA ROCHA FONOLITO COMO FERTILIZANTE ALTERNATIVO DE POTÁSSIO}

\section{INTRODUÇÃO}

Historicamente, a agricultura é uma das principais bases da economia do Brasil, principalmente pelas condições climáticas favoráveis. No entanto, o clima tropical, também, favorece a rápida decomposição das rochas que torna os solos brasileiros ácidos e pobres em nutrientes. Assim, para recuperar a produtividade dos solos são utilizadas elevadas quantidades de fertilizantes, classificando o Brasil, no ranking mundial de 2008, como o segundo maior consumidor de potássio (MARTINS, et. al. 2008).

No país, as duas principais reservas de potássio estão localizadas nos estados de Sergipe e Amazonas, porém essa última não é explorada devido a questões ambientais. $O$ depósito de Sergipe, em Taquari Vasouras, produziu 471 mil toneladas de $\mathrm{K}_{2} \mathrm{O}$ em 2007, a partir de silvita $(\mathrm{KCl})$ e da carnalita $\left[\mathrm{KMgCl}_{3} \cdot 6(\mathrm{H} 2 \mathrm{O})\right]$. No entanto, nesse ano, a demanda de fertilizantes potássicos no país foi da ordem de 4,7 milhões toneladas de $\mathrm{K}_{2} \mathrm{O}$ e esse número tende a crescer de forma contínua, ficando evidente a necessidade de buscar fontes alternativas deste nutriente, para diminuir a dependência externa do Brasil (MARTINS, et. al. 2008).

O uso direto de rochas na agricultura consiste em uma técnica de fertilização natural, denominada de rochagem (rocks for crops) ou remineralização. A técnica consiste na liberação de nutrientes, que compõem o pó de rocha, de forma gradual para o solo. De modo que, a velocidade que os fertilizantes minerais reagem com os solos é diretamente influenciada pela granulometria e pelo fluxo de água no sistema (van STRAATEN, 2007).

O Ministério da Agricultura, Pecuária e Abastecimento, por meio da instrução normativa $n^{\circ} 5$ de 23 de fevereiro de 2007, define as especificações dos fertilizantes minerais destinados à agricultura (BRASIL, 2007). Contudo, a regulamentação vigente não enquadra as novas fontes alternativas de insumos para a agricultura, mesmo tendo estes uma função nutricional e de remineralização dos solos, devido, principalmente, aos parâmetros estabelecidos atualmente para fertilizantes, como teores mínimos de nutrientes e solubilidade. Assim, o estímulo para o uso de pó de rochas na agricultura é baixo já que não existem normas para o registro destas novas fontes de insumos.

As rochas portadoras de potássio que ocorrem no território brasileiro são estudadas como alternativas de nutrientes para as plantas. Os estudos revelam que estas rochas podem ser aplicadas aos solos na forma pura, em misturas de rochas ou após serem submetidas a tratamentos químicos ou térmicos (MARTINS e THEODORO, 2010; SILVA, 2009; NOBRE, et. al. 2011). Os estudos de amostras como o flogopitito, resíduo de vermiculita e rocha potássica sugerem que estes materiais possuem potencial para uso como fertilizantes de liberação 
lenta, principalmente para a aplicação em culturas que demandem o potássio em longo prazo, como na cana-de-açúcar (da LUZ, et. al. 2010).

O fonolito é uma rocha de origem vulcânica que possui na sua composição mineralógica o predomínio de feldspato potássico, feldspato plagioclásios e feldspatóides. A origem do seu nome esta relacionada ao som que pode ser percurtido. $O$ elevado teor de óxidos alcalinos enquadra o fonolito como um fundente muito utilizado pelas indústrias cerâmicas (ANDRADE, et.al. 2005). O teor de potássio, cerca de $9 \%$ de $\mathrm{K}_{2} \mathrm{O}$, tem estimulado o estudo desta rocha como fonte alternativa de fertilizante de liberação lenta de potássio.

Neste contexto, o objetivo deste trabalho é avaliar as características físicas e químicas da rocha fonolito, proveniente do Planalto de Poços de Caldas, MG, a fim de adequar a rocha conforme os parâmetros granulométricos para fertilizantes minerais estabelecidos pelo Ministério da Agricultura, Pecuária e Abastecimento.

\section{MATERIAIS E MÉTODOS}

\section{Preparação da Rocha}

O estudo do fonolito do Planalto de Poços de Caldas, MG, teve início com o recebimento de aproximadamente $960 \mathrm{~kg}$ de amostra da rocha pelo CETEM/MCTI. A amostra da rocha foi submetida às etapas de preparação, Figura 2, para a obtenção de amostras com massa e granulometria adequadas para a realização dos ensaios (SAMPAIO, et.al. 2007).

$\mathrm{Na}$ etapa de britagem foram utilizados os britadores de mandíbula e de rolo, a fim de permitir a fragmentação da amostra até tamanho de partículas abaixo de 4,7 mm com pouca produção de materiais finos.

A homogeneização e quarteamento da amostra foram realizadas por meio de pilhas cônicas, seguida de uma pilha longitudinal para obter uma distribuição uniforme dos constituintes da rocha. A pilha cônica consiste em colocar o material sobre uma lona quadrada, em que os vértices são levantados alternadamente. A pilha longitudinal se resume em distribuir o material longitudinalmente, mediante sucessivas passagens. O quarteamento é, então, realizado pela divisão do material contido na pilha em alíquotas (SAMPAIO, et.al. 2007). Assim, após a etapa de quarteamento da amostra, britada e homogeneizada, foram obtidas alíquotas de aproximadamente 1 e $20 \mathrm{~kg}$. A fração remanescente da amostra britada e homogeneizada foi identificada e armazenada em local apropriado, como arquivo (TEIXEIRA, et. al. 2011). 


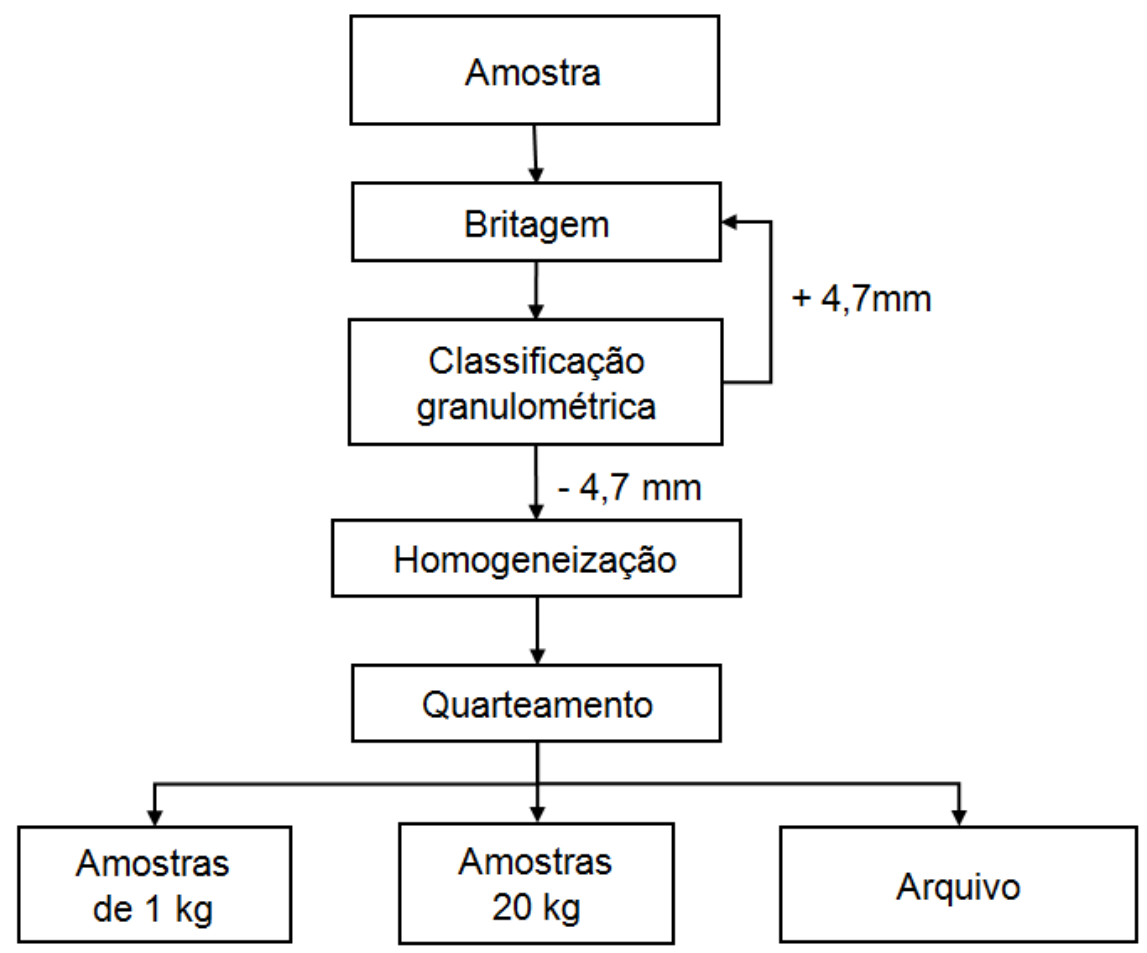

Figura 2 - Diagrama de fluxo das etapas de preparação das amostras.

\section{Caracterização Mineralógica}

$\mathrm{Na}$ caracterização da rocha fonolito foi realizado o ensaio de distribuição granulométrica, bem como determinada as fases mineralógicas que compõem as frações.

Para a análise de distribuição granulométrica foram utilizados $2 \mathrm{~kg}$ de amostra da rocha britada, com granulometria abaixo de $4,7 \mathrm{~mm}$. O ensaio foi realizado por peneiramento a úmido, com abertura das peneiras de 3,3 a 0,038 $\mathrm{mm}$ e um peneirador vibratório. Todas as frações obtidas no ensaio de distribuição granulométrica foram secas em estufa, à temperatura de $70^{\circ} \mathrm{C}$, e pesadas para a realização dos cálculos de porcentagens passantes nas peneiras (SAMPAIO, et.al. 2007).

A fim de verificar diferenças nas características mineralógicas, as frações da rocha fonolito foram agrupadas em 5 amostras. Os tamanhos de partículas das frações e suas respectivas identificações estão relacionados na Tabela 1. Os sinais de (-) e (+) que antecedem os valores da abertura das peneiras representam, respectivamente, as frações passantes e retidas obtidas na distribuição granulométrica da rocha fonolito. Para a caracterização das frações, as amostras foram moídas até tamanho de partículas abaixo de 0,15 mm.

Tabela 1 - Identificação das frações agrupadas da distribuição granulométrica do fonolito. 


\begin{tabular}{|l|c|}
\hline Código das Frações & Frações Agrupadas (mm) \\
\hline (a) & $-4,7+1,7$ \\
\hline (b) & $-1,7+0,58$ \\
\hline (c) & $-0,58+0,25$ \\
\hline (d) & $-0,25+0,075$ \\
\hline (e) & $-0,075$ \\
\hline
\end{tabular}

A identificação das fases mineralógicas constituintes das frações, da distribuição granulométrica, foi realizada no equipamento DRX Ultima IV, Rigaku, com passo do goniômetro de $0,02^{\circ}$ em $2 \theta$, com $0,5 \mathrm{~s}$ de tempo de contagem e radiação $\mathrm{Cu}$-k $\alpha(\lambda=1,5418$ $\AA$; $40 \mathrm{kV} / 40 \mathrm{~mA}$ ), na faixa angular $(2 \theta)$ variando de $5^{\circ}$ a $80^{\circ}$. As interpretações dos difratogramas foram efetuadas por comparação com os padrões do banco de dados do ICSD Web.

A composição química das frações da distribuição granulométrica foram determinadas em um espectrômetro de fluorescência de raios X PanAlytical, modelo Axios, com tubo de Rh, utilizando um detector de dispersão de comprimento de onda (WDS). As amostras foram preparadas por prensagem utilizando como aglomerador o ácido bórico P.A., nas análises foi utilizado o método Standardless.

As análises por espectrometria no infravermelho, das frações da distribuição granulométrica, foram realizadas em um equipamento Magna 760, da marca Nicolet, na região de 4000 a $400 \mathrm{~cm}^{-1}$, com resolução de $4 \mathrm{~cm}^{-1}$. Os espectros foram obtidos em pastilhas de $\mathrm{KBr}$ anidro.

\section{Curvas de Moagem}

Os ensaios de moagem foram realizados por meio de uma unidade motora com velocidade controlada, um moinho de corpo cilíndrico de dimensões de 15,05 X 29,75 cm (diâmetro X comprimento), um corpo moedor de 10 barras, com dimensões de 2,50 X 29,35 $\mathrm{cm}$ (diâmetro $X$ comprimento) e um cronômetro para controle do tempo de moagem das amostras. As alíquotas da rocha foram submetidas às moagens a úmido e a seco, por 15, 30, 45 e 60 minutos, com velocidade de rotação do moinho de barras de $70 \mathrm{rpm}$. A massa das barras utilizadas na moagem foi de cerca de $1 \mathrm{~kg}$, de modo que a razão entre a massa da amostra e das barras foi de 1:1.

Após a moagem, foram realizados os ensaios de distribuição granulométrica, por via úmida e peneiras segundo a série Tyler, 3,3 a 0,038 mm. Os valores da distribuição 
granulométrica no tempo de moagem zero correspondem à distribuição granulométrica da rocha britada com partículas inferiores a $4,7 \mathrm{~mm}$, ou seja, antes do ensaio de moagem.

Os ensaios de moagem a úmido foram realizados com polpas contendo cerca de $1,0 \mathrm{~kg}$ da rocha britada e $1 \mathrm{~L}$ de água e os ensaios de moagem a seco foram realizados com cerca 1,0 $\mathrm{kg}$ da rocha britada. As frações retidas nas peneiras da distribuição granulométrica foram secas a $70{ }^{\circ} \mathrm{C}$ e pesadas.

\section{RESULTADOS E DISCUSSÕES}

\section{Distribuição Granulométrica}

A análise dos resultados obtidos na distribuição granulométrica da rocha britada, com granulometria inferior a 4,7 mm, Figura 2, revela a larga distribuição no tamanho das partículas. Foi observado que aproximadamente $8 \%$ das partículas possuem dimensão inferior a 0,3 $\mathrm{mm}$, sendo que menos de $2 \%$ possuem partículas inferiores a 0,038 $\mathrm{mm}$. Ainda pode ser observado que cerca de $50 \%$ das partículas possuem granulometria superior a $2,4 \mathrm{~mm}$.

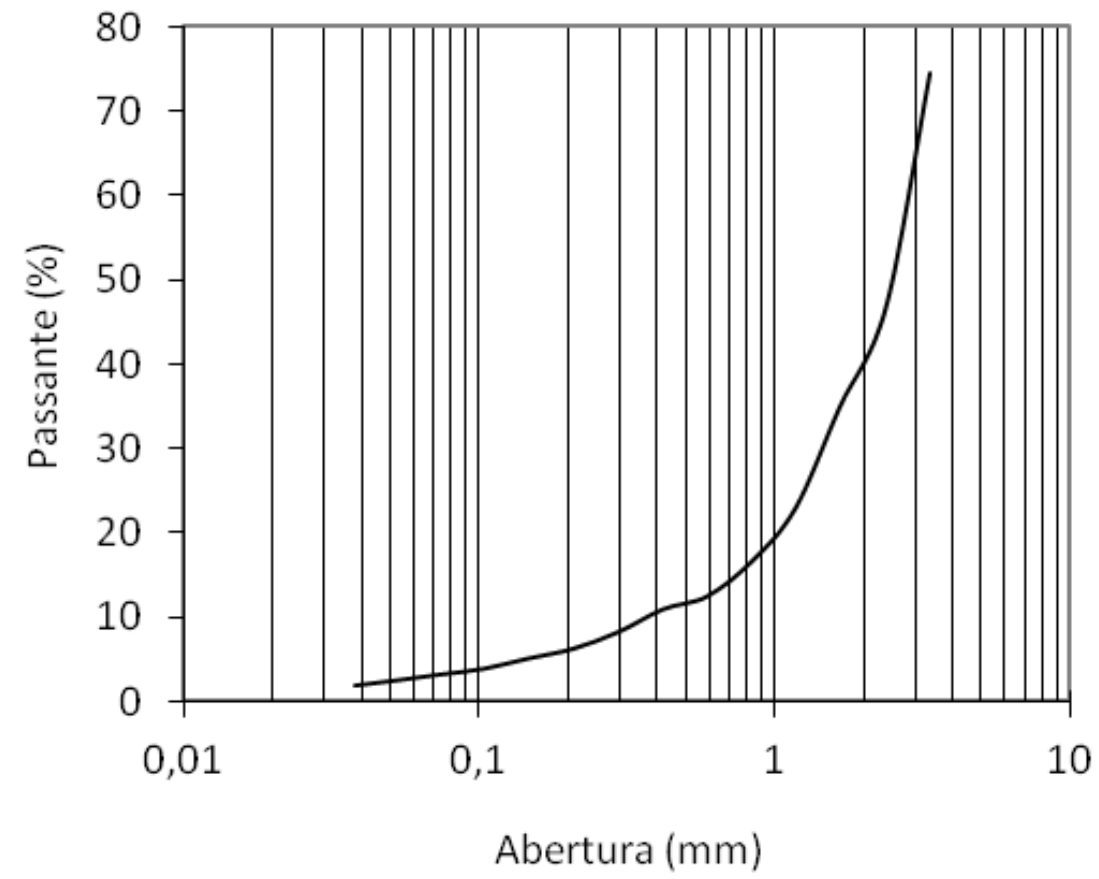

Figura 2 - Representação gráfica da distribuição granulométrica do fonolito.

Os difratogramas das frações da distribuição granulométrica do fonolito estão ilustrados na faixa angular (20) variando de $10^{\circ}$ a $45^{\circ}$, Figura 3. Na análise dos difratogramas foi verificado que as frações da distribuição granulométrica possuem mineralogia semelhante às fases identificadas no difratograma da rocha, global. Assim, do mesmo modo, os constituintes identificados nas frações da distribuição granulométrica são: microclínio e ortclásio $\left(\mathrm{KAISi}_{3} \mathrm{O}_{8}\right)$, andaluzita $\left(\mathrm{Al}_{2} \mathrm{SiO}_{5}\right)$, nefelina $\left((\mathrm{Na}, \mathrm{K}) \mathrm{AlSiO}_{4}\right)$ e andesina $\left((\mathrm{Na}, \mathrm{Ca})(\mathrm{Si}, \mathrm{Al})_{4} \mathrm{O}_{8}\right)$ (TEIXEIRA, et. al. 2011). 
$\mathrm{Na}$ fração (c), $-0,58+0,25 \mathrm{~mm}$, foi verificado o aumento da intensidade do pico referente à sodalita $\left(\mathrm{Na}_{4} \mathrm{Al}_{3} \mathrm{Si}_{3} \mathrm{O}_{12} \mathrm{Cl}\right)$ em $14,18^{\circ}$, bem como o aumento da intensidade do pico referente à Nefelina $\left[(\mathrm{Na}, \mathrm{K}) \mathrm{AlSiO}_{4}\right]$ em $38,34^{\circ}$.

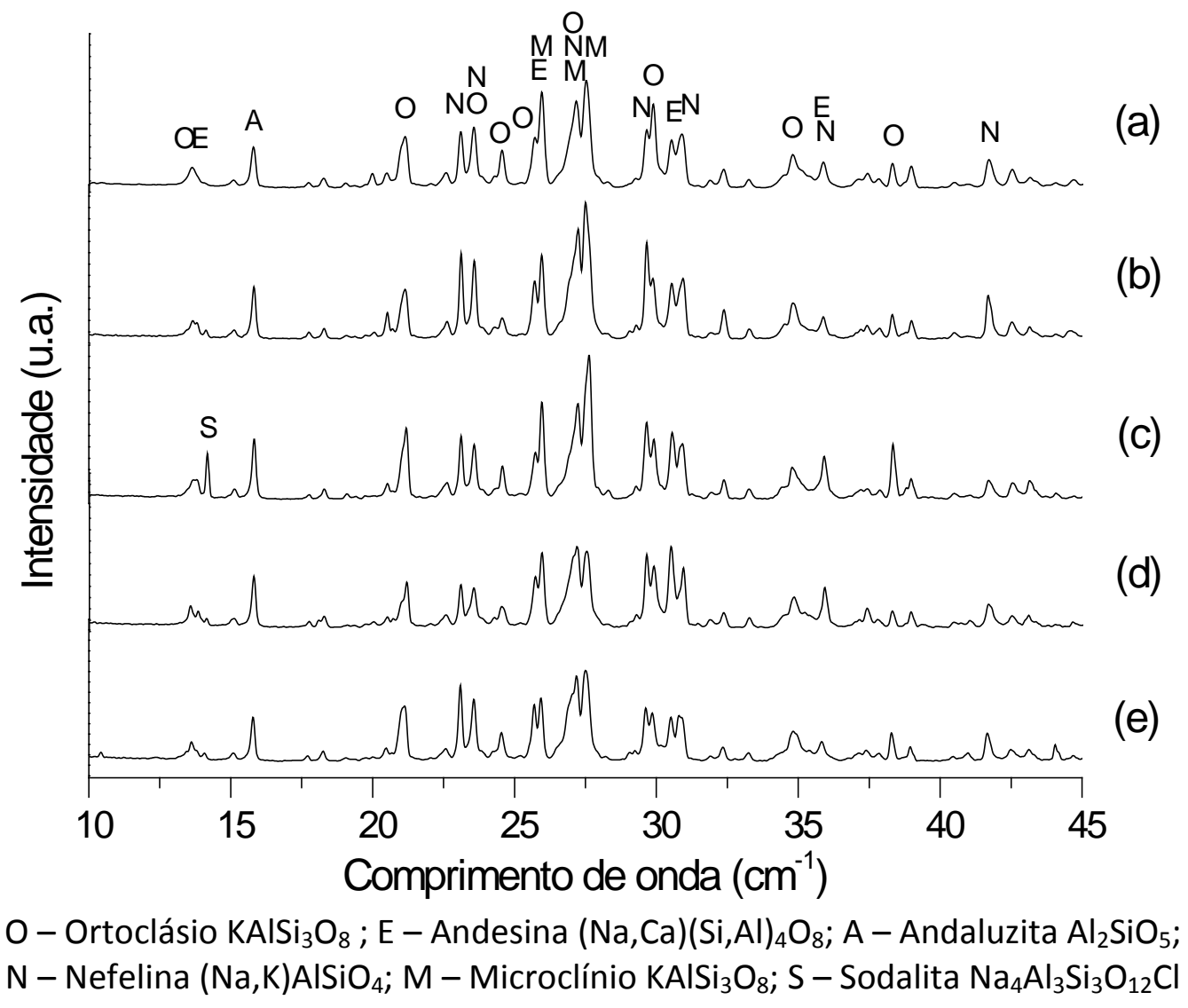

Figura 3 - Difratogramas de raios $X$ das frações da distribuição granulométrica da rocha, radiação Cu-k $\alpha(\lambda=1,5418 \AA$ ) .

Os resultados da composição química $(\% \mathrm{~m} / \mathrm{m})$ das frações da distribuição granulométrica estão relacionados na Tabela 2. Os resultados obtidos pela técnica de espectrometria de fluorescência de raios $X$ estão expressos em porcentagem de óxidos, considerando a forma de óxidos mais estáveis, e normalizados a $100 \%$, com o intuito de fornecer uma referência dos elementos constituintes do material.

Tabela 2 - Composição química das frações da distribuição granulométrica da rocha.

\begin{tabular}{|l|l|l|l|l|l|}
\hline \multirow{2}{*}{ Composição } & \multicolumn{5}{|c|}{ Frações } \\
\cline { 2 - 6 } & (a) & (b) & (c) & (d) & (e) \\
\cline { 2 - 5 } & \multicolumn{5}{|c|}{$\%(\mathrm{~m} / \mathrm{m})$} \\
\hline
\end{tabular}




\begin{tabular}{|c|c|c|c|c|c|}
\hline $\mathrm{SiO}_{2}$ & 53,4 & 53,3 & 54,1 & 51,2 & 52,5 \\
\hline $\mathrm{Al}_{2} \mathrm{O}_{3}$ & 22,6 & 22,7 & 22,9 & 21,4 & 22,5 \\
\hline $\mathrm{K}_{2} \mathrm{O}$ & 6,9 & 7,1 & 7,1 & 8,3 & 7,2 \\
\hline $\mathrm{Na}_{2} \mathrm{O}$ & 7,8 & 7,9 & 7,7 & 7,0 & 7,4 \\
\hline $\mathrm{Fe}_{2} \mathrm{O}_{3}$ & 4,8 & 4,3 & 3,6 & 6,1 & 5,0 \\
\hline $\mathrm{CaO}$ & 1,4 & 1,5 & 1,4 & 2,0 & 1,6 \\
\hline $\mathrm{MgO}$ & 0,16 & 0,12 & 0,13 & 0,15 & 0,26 \\
\hline SrO & 0,16 & 0,18 & 0,15 & 0,27 & 0,17 \\
\hline $\mathrm{MnO}$ & 0,22 & 0,22 & 0,21 & 0,32 & 0,25 \\
\hline $\mathrm{TiO}_{2}$ & 0,47 & 0,47 & 0,43 & 0,62 & 0,54 \\
\hline $\mathrm{ZrO}_{2}$ & 0,14 & 0,15 & 0,13 & 0,24 & 0,15 \\
\hline Sulfito & 0,27 & 0,33 & 0,25 & 0,33 & 0,36 \\
\hline Cloreto & 0,11 & 0,12 & 0,12 & 0,14 & 0,12 \\
\hline $\mathrm{P}_{2} \mathrm{O}_{5}$ & 0,05 & 0,06 & 0,06 & 0,07 & 0,07 \\
\hline $\mathrm{Nb}_{2} \mathrm{O}_{5}$ & 0,04 & 0,04 & 0,03 & 0,06 & 0,04 \\
\hline $\mathrm{ZnO}$ & 0,02 & 0,03 & 0,02 & 0,04 & 0,05 \\
\hline $\mathrm{Rb}_{2} \mathrm{O}$ & 0,02 & 0,02 & 0,02 & 0,03 & 0,02 \\
\hline Perda ao fogo & 1,3 & 1,4 & 1,8 & 1,8 & 1,9 \\
\hline
\end{tabular}

$\mathrm{Na}$ análise dos resultados obtidos para as frações da ditribuição granulométrica foi verificado que na fração $(\mathrm{d}),-0,25+0,075 \mathrm{~mm}$, o teor de $\mathrm{K}_{2} \mathrm{O}(8,3 \%)$ é superior em relação aos valores obtidos para as outras frações.

A análise do espectro de infravermelho das frações da distribuição granulométrica, Figura 4, sugere que as principais vibrações identificadas na amostra estão relacionadas aos minerais do grupo feldspato, corroborando com os resultados obtidos pela técnica de difração de raios $X$. 


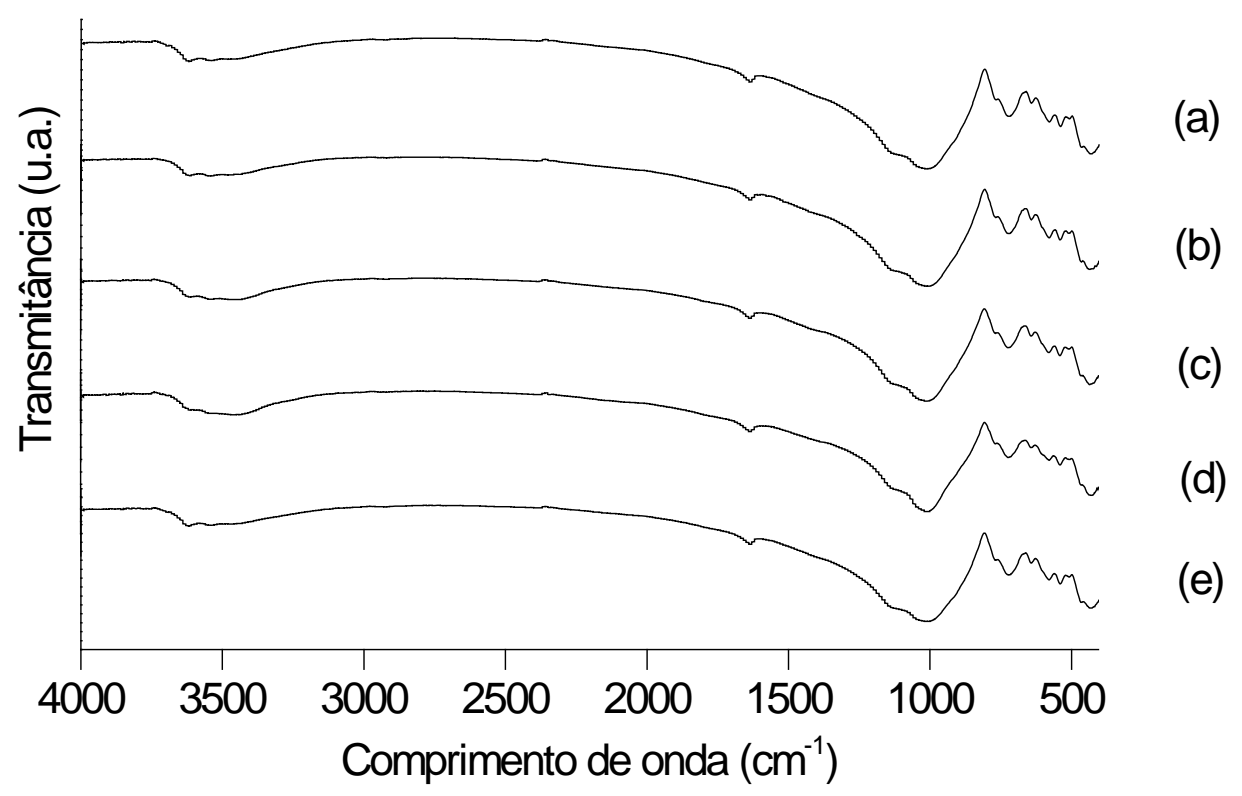

Figura 4 - Espectros no infravermelho da rocha fonolito e das frações da distribuição granulométrica.

As bandas com comprimento de onda entre 3650 e $3300 \mathrm{~cm}^{-1}$ são características das vibrações de estiramento das ligações $\mathrm{O}-\mathrm{H}$ e a banda em aproximadamente $1635 \mathrm{~cm}^{-1}$ se refere à deformação da ligação $\mathrm{O}-\mathrm{H}$. As bandas de absorção com maior intensidade nos espectros de infravermelho das amostras ocorrem entre 1200 e $900 \mathrm{~cm}^{-1}$ e correspondem às vibrações do estiramento assimétrico da ligação Si-O-(Si ou Al). A banda em aproximadamente $765 \mathrm{~cm}^{-1}$ corresponde ao estiramento simétrico da ligação Si-O-Si e em aproximadamente 721 $\mathrm{cm}^{-1}$ corresponde ao estiramento da ligação Al-O coordenado octaedricamente. A banda em $583 \mathrm{~cm}^{-1}$ aproximadamente corresponde à deformação da ligação O-(Si ou Al)-O, que é característica de feldspatos microclínio. A deformação da ligação O-Si-O é identificada pela banda em aproximadamente $540 \mathrm{~cm}^{-1}$ e as vibrações de deformação da ligação (Si ou Al)-O são identificadas pelas bandas em 464 e $430 \mathrm{~cm}^{-1}$.

\section{Curvas de Moagem}

Os resultados dos ensaios de moagem após 15, 30, 45 e 60 minutos, por via úmida estão ilustrados na Figura 5 e os resultados das moagens por via seca estão ilustrados na Figura 6. A distribuição granulométrica no tempo de moagem zero corresponde aos valores da rocha britada, com partículas inferiores a $4,7 \mathrm{~mm}$, ou seja, amostra global antes do ensaio de moagem. 


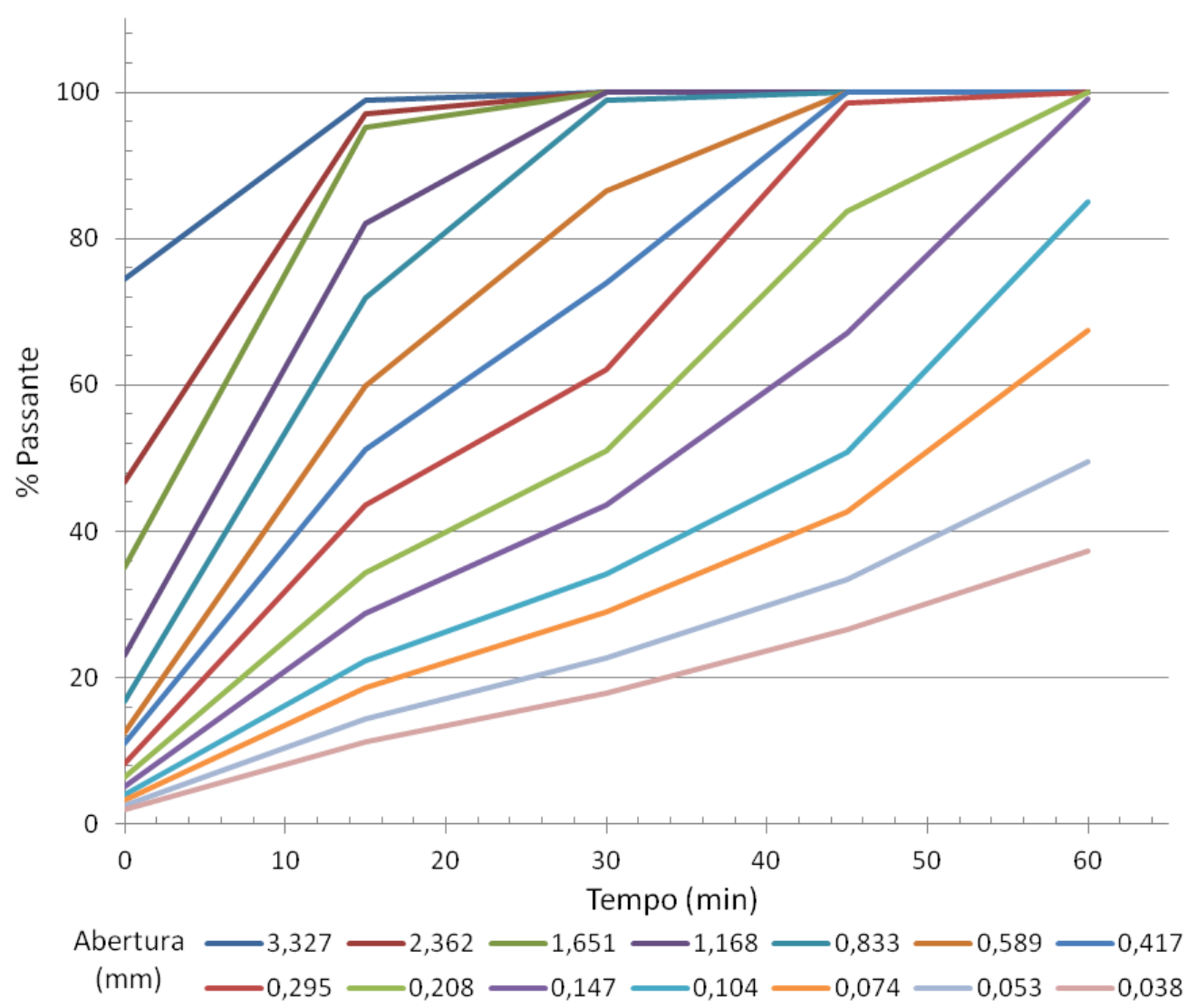

Figura 5 - Representação gráfica dos nos ensaios de moagem a úmido da rocha fonolito.

A análise dos resultados, da moagem a úmido, indica que após aproximadamente 20 minutos de moagem em moinho de barras, a rocha britada possui $100 \%$ das partículas com dimensões inferiores a 1,7 mm e 50\% das partículas com dimensões inferiores a 0,3 mm. Após 30 minutos de moagem, $100 \%$ das partículas possuem tamanhos inferiores a 0,84 mm. Após 45 minutos de moagem, cerca de $100 \%$ das partículas possuem tamanhos inferiores $0,3 \mathrm{~mm}$ e aproximadamente $70 \%$ das partículas possuem tamanhos inferiores a 0,15 mm. Após 60 minutos de moagem, $100 \%$ das partículas possuem dimensões inferiores a 0,15 mm e cerca de $40 \%$ das partículas possuem tamanhos inferiores a $0,038 \mathrm{~mm}$. 


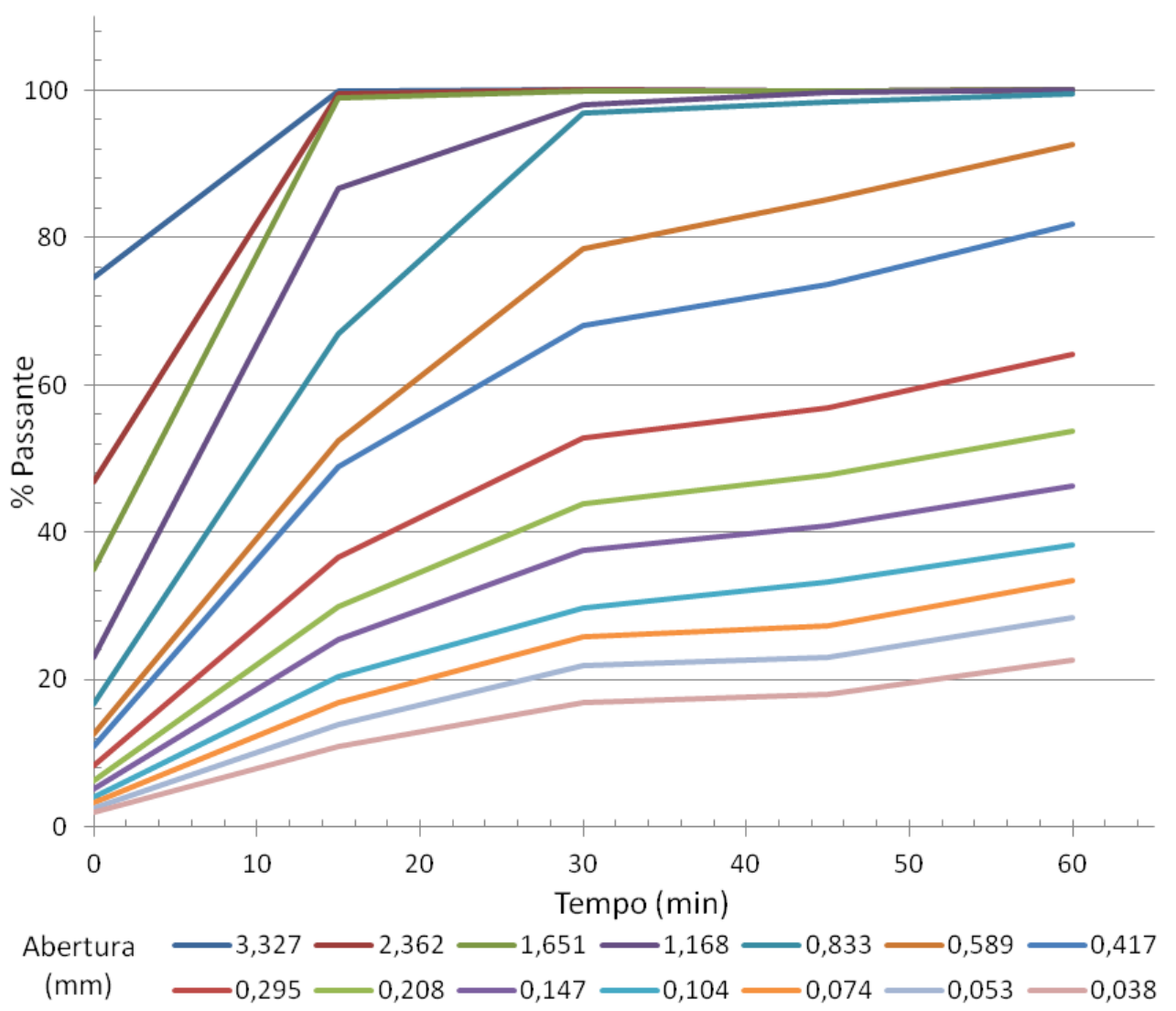

Figura 6 - Representação gráfica dos ensaios de moagem a seco da rocha fonolito.

A análise dos resultados, da moagem a seco, indica que após aproximadamente 20 minutos de moagem em moinho de barras, a rocha britada possui $100 \%$ das partículas com dimensões inferiores a $1,7 \mathrm{~mm}$ e cerca de $50 \%$ das partículas com dimensões inferiores a 0,42 $\mathrm{mm}$. Após 30 minutos de moagem, 100\% das partículas possuem dimensões inferiores a 0,84 $\mathrm{mm}$. Depois de 60 minutos de moagem, cerca de 90\% das partículas possuem tamanhos inferiores $0,58 \mathrm{~mm}$ e aproximadamente $20 \%$ das partículas possuem tamanhos inferiores a $0,038 \mathrm{~mm}$.

Cabe ressaltar ainda, que depois de 15 minutos, tanto na moagem a úmido como na moagem a seco, $100 \%$ das partículas possuem dimensões inferiores a $2 \mathrm{~mm}$. Entretanto, depois de 60 minutos, a moagem a úmido resultou em 100\% das partículas com dimensões inferiores a 0,15 mm, enquanto que na moagem a seco, foram obtidas aproximadamente $50 \%$ das partículas com essa granulometria. Portanto, a análise destes resultados revela que a moagem a úmido gera maior quantidade de partículas finas, em relação à moagem a seco, sendo importante também reforçar o papel da água em diminuir as forças de atração entre as partículas, impedindo a aglomeração.

\section{CONCLUSÃO}


As frações da distribuição granulométrica da rocha fonolito do Planalto de Poços de Caldas, MG, possuem composições químicas e mineralógicas semelhantes. As frações possuem cerca de $7,0 \%$ de $\mathrm{K}_{2} \mathrm{O}$, além de nutrientes como o silício, ferro, cálcio e manganês, que são requeridos pelas plantas. Entretanto, ainda é necessária uma análise da liberação de metais potencialmente tóxicos pela rocha, como por exemplo, cromo e cádmio, quando esta é colocada em contato com extratores adequados, visando se avaliar se estes metais serão acumulados no solo no caso da aplicação desta rocha (TEIXEIRA, et. al. 2012).

Os resultados de DRX indicam que a mineralogia das frações é constituída principalmente por feldspatos potássicos corroborando com as principais vibrações identificadas nos espectros de infravermelho.

$\mathrm{Na}$ análise das curvas de moagem foi observado que na moagem a úmido são geradas maiores quantidades de partículas finas, se comparada com a moagem a seco. Sendo que, após 15 minutos de moagem, em ambas as condições, são obtidas 100\% das partículas com dimensões inferiores a $2 \mathrm{~mm}$, que corresponde a especificação granulométrica para fertilizantes minerais simples, definidas pelo Ministério da Agricultura, Pecuária e Abastecimento.

\section{AGRADECIMENTOS}

Ao CNPq e CAPES, pelo apoio financeiro e CETEM/MCTI pela infraestrutura para o desenvolvimento deste trabalho. À FERBASA pelo fornecimento das amostras.

\section{REFERÊNCIAS BIBLIOGRÁFICA}

1. ANDRADE, P.M.; NETO, H.S.N.; MONTEIRO, S.N.; VIEIRA, C.M.F. Efeito da Adição de Fonolito na Sinterização de Argila Caulinítica. Cerâmica, v. 51, p. 361-370, 2005.

2. BRASIL. Instrução Normativa n. 5, de 23 de fevereiro de 2007. Diário Oficial da União, República Federativa do Brasil, Brasília-DF, 01 mar. 2007. Seção 1, p. 10-21.

3. da LUZ, A.B.; BALTAR, C.A.M.; BERTOLINO, L.C. orgs. Anais Simpósio de Minerais Industriais do Nordeste, 2., 2010, Campina Grande-PB: CETEM/UFPE, 2010. p. 115-152.

4. MARTINS, E.S.; THEODORO, S.H. eds. Anais Congresso Brasileiro de Rochagem, 1., 2009, Planaltina-DF: Embrapa Cerrados, 2010. p. 321.

5. MARTINS, E.S.; OLIVEIRA, C.G.; RESENDE, A.V.; MATOS, M.S.F. Agrominerais - Rochas silicáticas como fontes minerais alternativas de potássio para a agricultura. In: da Luz, A.B.; Lins, F.F., eds. Rochas e Minerais Industriais: usos e especificações. 2. ed. Rio de Janeiro: CETEM/MCTI, 2008. p. 205-223.

6. NOBRE, L.L.S.; ARAÚJO, F.S.D.; DANTAS, A.P.A.; LEITE, J.Y.P. Análise do Rejeito de Cerâmica Vermelha e sua Aplicação como Fonte de Potássio na Agricultura. Holos. ano 27. v. 5. p. 39, 2011. 
7. SAMPAIO, J.A.; FRANÇA, S.C.A.; BRAGA, P.F.A. eds. Tratamento de Minérios: Práticas Laboratoriais. Rio de Janeiro: CETEM/MCTI, 2007. p. 570.

8. SILVA, A.A.S. Caracterização de Flogopitito da Bahia para Uso como Fertilizante Alternativo de Potássio. 2009. 97 p. Dissertação (Mestrado em Química) - Instituto de Química, Universidade Federal do Rio de Janeiro, Rio de Janeiro.

9. van STRAATEN, P. Potassium. In: van STRAATEN, P. Agrogeology: the use of rocks for crops. Canadá: Enviroquest Ltd., 2007. cap.5, p. 165-200.

10. TEIXEIRA, A.M.S.; SAMPAIO, J.A.; GARRIDO, F.M.S.; MEDEIROS, M.E. Technological Characterization of Phonolite Rock to be Applied as Source of Nutrients to the Brazilian Agriculture. in EPD Congress 2011 (eds S. N. Monteiro, D. E. Verhulst, P. N. Anyalebechi and J. A. Pomykala), John Wiley \& Sons, Inc., Hoboken, NJ, USA. 2011. v. 1. p. 81-86. doi: 10.1002/9781118495285.ch10

11. TEIXEIRA, A.M.S.; GARRIDO, F.M.S.; MEDEIROS, M.E.; SAMPAIO, J.A. Caracterização e Classificação quanto ao Risco Ambiental do Estéril da Mina de Cromita do Município de Andorinha, Bahia. Quím. Nova. v. 35. n. 9. p. 1749-1799, 2012. 